\title{
Sympathetic Coronary Vasoconstriction after Adrenergic Beta Blockade
}

\author{
Kizuku Kuramoto, Kazuhiko Murata, Jun Fujii, Hiroshi Kurihara, \\ Shin-ichi Kimata, Satoru Matsushita, Morio Kuramochi, \\ Masao Ikeda and Kiku Nakao
}

\author{
The Third Department of Internal Medicine (Prof. K. Nakao), \\ Faculty of Medicine, University of Tokyo, Tokyo
}

\begin{abstract}
Sympathetic control of the coronary circulation was studied by eliminating the inotropic and chronotropic effects of sympathetic stimulation with adrenergic beta blockade. A remarkable vasoconstrictor effect of the left sympathetic nerve stimulation was observed after an intracoronary injection of propranolol, while the effect of the right sympathetic nerve stimulation was less prominent. The late increase in coronary flow after the cessation of the stimulation was observed to a lesser extent after the adrenergic beta blockade, while the blood pressure and heart rate remained unchanged. The sympathetic coronary vasoconstriction was almost abolished by adrenergie alpha blockade.
\end{abstract}

Sympathetic control of the coronary circulation has been investigated repeatedly by using various experimental preparations. ${ }^{1-8}$ However, the direct effect of sympathetic nerve stimulation on the coronary vessel is complicated by the mechanical effect due to the changes in myocardial contractility and heart rate.

The purpose of the present experiments was to investigate a direct effect of sympathetic stimulation on the coronary circulation by eliminating its inotropic and chronotropic effects with adrenergic beta blockade.

\section{Methods}

Thirteen dogs weighing from 10 to $16 \mathrm{~kg}$ were anesthetized with intravenous sodium thiopental $(30 \mathrm{mg} / \mathrm{kg})$. Under positive pressure respiration with a constant volume respirator bilateral thoracotomy was performed. After intravenous injection of heparin $(6 \mathrm{mg} / \mathrm{kg})$, a modified Gregg type cannula with convoluted tip was inserted snugly into the left coronary ostium via the right subclavian artery. The left coronary artery was perfused with animal's own blood led from the left subclavian artery, an electromagnetic flowmeter being inserted in the perfusion circuit. Blood pressure was measured at the level of the aortic arch. The left ventricular pressure and the first derivative of the left

Received for publication, September 30, 1966. 
ventricular pressure $(d p / d t)$ were measured by direct needle puncture of the left ventricle.

The left and right common ansa subclavia or its anterior limb were disconnected from the stellate ganglion, and stimulated for 15 sec with rectangular impulses of $3 \mathrm{msec}$ in duration. The voltage and frequency of the stimulation were 6 to 8 volts, and $20 \mathrm{cycles} / \mathrm{sec}$, respectively. Propranolol ( 3 to $5 \mathrm{mg}$ ) was injected into the left coronary artery as an adrenergic beta blockade, and ergot alkaloids (hydergine 0.3 to $0.6 \mathrm{mg}$, consisting of dihydroergocornine, dihydroergocristine, and dihydroergokryptine in equal proportions) were used to block the adrenergic alpha receptor.

\section{Results}

\section{1) Control response of the left coronary flow to the left sympathetic stimulation}

Average responses to the left sympathetic stimulation in 11 dogs are summarized in Table 1. Representative tracings are shown in Fig. 1. In the phase 1, 2 to 4 seconds after the beginning of stimulation, mean coronary flow decreased by $5.4 \%$ with a slight increase in heart rate, blood pressure, and $d p / d t$ of the left ventricle by $3.5 \%, 2.0 \%$, and $3.3 \%$ respectively; mean coronary vascular resistance increased by $8.4 \%$. In the second phase, 5 to 10 seconds after the beginning of the stimulation, coronary flow increased by $35.1 \%$ with increase in blood pressure by $16.4 \%$; coronary vascular resistance decreased by $14.4 \%$. In the third phase, soon after the end of the stimulation, coronary flow remained at an increased level of $29.8 \%$, when blood pressure returned to the previous level. In the fourth phase, 10 to 30 seconds after the cessation of the stimulation, coronary flow increased markedly by $86 \%$, and coronary vascular resistance decreased by $39.4 \%$.

TABLE 1. Effect of left sympathetic stimulation on coronary circulation

\begin{tabular}{|c|c|c|c|c|c|}
\hline & \multirow{2}{*}{ Control } & \multicolumn{2}{|c|}{ During stimulation } & \multicolumn{2}{|c|}{ After stimulation } \\
\hline & & 1 & 2 & 3 & 4 \\
\hline Heart rate & $161 / \mathrm{min}$ & 3.5 & 8.2 & 11.8 & 5.8 \\
\hline $\begin{array}{l}\text { Blood } \\
\text { pressure }\end{array}$ & $94 \mathrm{mmHg}$ & 2.0 & 16.4 & -3.5 & 12.9 \\
\hline $\begin{array}{l}\text { Coronary } \\
\text { flow }\end{array}$ & $40 \mathrm{ml} / \mathrm{min}$ & -5.4 & 35.1 & 29.8 & 86.0 \\
\hline $\begin{array}{l}\text { Coronary } \\
\text { resistance }\end{array}$ & $\begin{array}{l}2.73 \mathrm{mmHg} \\
/ \mathrm{ml} / \mathrm{min}\end{array}$ & 8.4 & -14.4 & -27.5 & -39.4 \\
\hline$d p / d t$ & $1,325 \mathrm{mmHg} / \mathrm{sec}$ & 3.3 & 43.1 & 27.7 & 38.8 \\
\hline
\end{tabular}

\section{2) Effect of sympathetic stimulation after adrenergic beta blockade}

Intracoronary injection of 3 to $5 \mathrm{mg}$ of propranolol increased coronary flow 


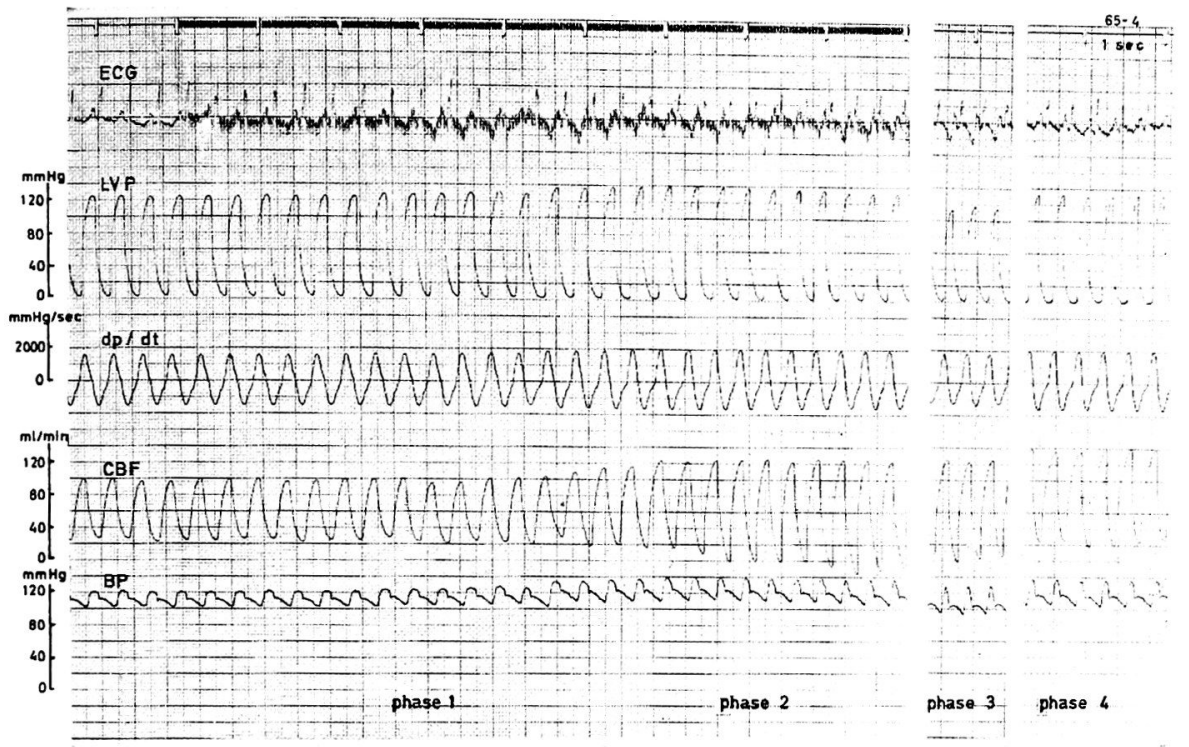

Fig. 1. Record showing the electrocardiogram (ECG), left ventricular pressure (LVP) and its $d p / d t$, coronary blood flow (CBF), and blood pressure (BP) following left sympathetic stimulation. Biphasic increase in coronary flow was observed during and after the stimulation.

TABLE 2. Effect of left sympathetic stimulation on coronary circulation after intracoronary injection of adrenergic beta blocking agent

\begin{tabular}{|c|c|c|c|c|c|}
\hline & \multirow{2}{*}{ Control } & \multicolumn{2}{|c|}{ During stimulation } & \multicolumn{2}{|c|}{ After stimulation } \\
\hline & & 1 & 2 & 3 & 4 \\
\hline Heart rate & $107 / \mathrm{min}$ & -1.2 & 6.4 & 11.5 & 0.6 \\
\hline $\begin{array}{l}\text { Blood } \\
\text { pressure }\end{array}$ & $91 \mathrm{mmHg}$ & -0.9 & 0.5 & -3.7 & 4.2 \\
\hline $\begin{array}{l}\text { Coronary } \\
\text { flow }\end{array}$ & $35 \mathrm{ml} / \mathrm{min}$ & -8.2 & -32.9 & -20.5 & 37.6 \\
\hline $\begin{array}{l}\text { Coronary } \\
\text { resistance }\end{array}$ & $\begin{array}{r}3.14 \mathrm{mmHg} \\
/ \mathrm{ml} / \mathrm{min}\end{array}$ & 6.5 & 55.1 & 22.9 & -16.4 \\
\hline$d p / d t$ & $883 \mathrm{mmHg} / \mathrm{sec}$ & 2.2 & 2.9 & 14.5 & 14.8 \\
\hline
\end{tabular}

during the injection with a slight depression of blood pressure and moderate bradycardia. The maximum $d p / d t$ of the left ventricle decreased from 1,325 to $883 \mathrm{~mm} \mathrm{Hg} / \mathrm{sec}$, while blood pressure revealed a slight change from 94 to $91 \mathrm{~mm}$ $\mathrm{Hg}$ on the average. The control values and average responses in 6 dogs are summarized in Table 2. Representative tracings are shown in Fig. 2. Heart rate, blood pressure and $d p / d t$ of the left ventricle were essentially unchanged during sympathetic stimulation, while the coronary flow decreased by $32.9 \%$ in 


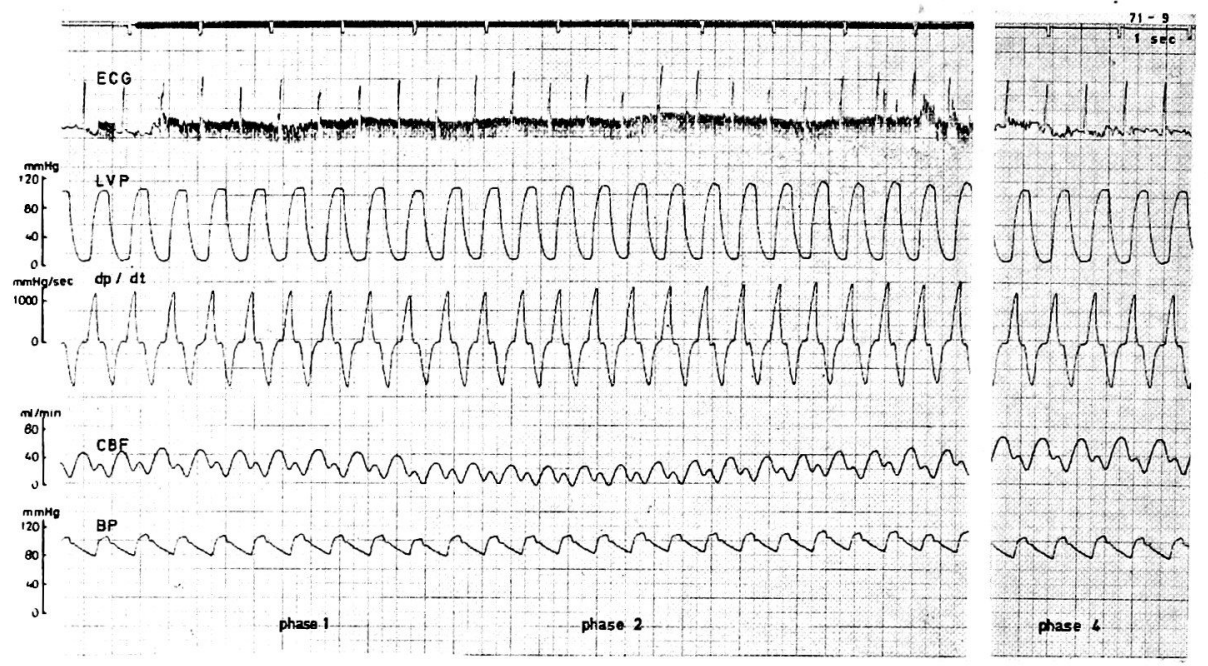

Fig. 2. Record showing the electrocardiogram (ECG), left ventricular pressure (LVP) and its $d p / d t$, coronary blood flow (CBF), and blood pressure (BP) in left sympathetic stimulation after intracoronary injection of propranolol. Note the marked decrease in coronary flow at the second phase.

TABLE 3. Effect of right sympathetic stimulation on coronary circulation after intracoronary injection of adrenergic beta blocking agent

\begin{tabular}{|c|c|c|c|c|c|}
\hline & \multirow{2}{*}{ Control } & \multicolumn{2}{|c|}{ During stimulation } & \multicolumn{2}{|c|}{ After stimulation } \\
\hline & & 1 & 2 & 3 & 4 \\
\hline Heart rate & $108 / \mathrm{min}$ & 4.4 & 23.1 & 26.7 & 11.7 \\
\hline $\begin{array}{l}\text { Blood } \\
\text { pressure }\end{array}$ & $94 \mathrm{mmHg}$ & 0 & -2.8 & -7.6 & -3.0 \\
\hline $\begin{array}{l}\text { Coronary } \\
\text { flow }\end{array}$ & $31 \mathrm{ml} / \mathrm{min}$ & -10.3 & -9.8 & -6.4 & 13.8 \\
\hline $\begin{array}{l}\text { Coronary } \\
\text { resistance }\end{array}$ & $\begin{array}{r}3.59 \mathrm{mmHg} \\
/ \mathrm{ml} / \mathrm{min}\end{array}$ & 13.8 & 24.8 & -2.5 & -9.8 \\
\hline$d p / d t$ & $1,045 \mathrm{mmHg} / \mathrm{sec}$ & -0.3 & 8.2 & 0.7 & 3.8 \\
\hline
\end{tabular}

the second phase, the coronary vascular resistance being increased by $55.1 \%$. However, the coronary flow increased by $37.6 \%$ in the fourth phase without significant changes in heart rate and blood pressure. The right sympathetic stimulation after propranolol decreased coronary flow only by $9.8 \%$ in the second phase, and coronary vascular resistance increased by $24.8 \%$ on the average, while in the fourth phase coronary flow increased by $13.8 \%$, and coronary vascular resistance decreased by $9.8 \%$ (Table 3). Since propranolol was injected into the left coronary artery, heart rate increased by $23 \%$ in the second phase; blood pressure and $d p / d t$ of the left ventricular pressure remained unchanged. 
3) Effect of sympathetic stimulation after adrenergic beta and alpha blockade

The observed decrease in coronary flow during left sympathetic stimulation was almost abolished after additional intracoronary injection of hydergine to the adrenergic beta blocked heart. The average decrease in coronary flow in 5 dogs was $6.7 \%$, and coronary vascular resistance increased by $11.4 \%$ (Table 4 ). The increase in coronary flow after the sympathetic stimulation was also diminished after alpha blockade.

TABLE 4. Effect of left sympathetic stimulation on coronary circulation after intracoronary injection of adrenergic beta and alpha blocking agent

\begin{tabular}{|c|c|c|c|c|c|}
\hline & \multirow{2}{*}{ Control } & \multicolumn{2}{|c|}{ During stimulation } & \multicolumn{2}{|c|}{ After stimulation } \\
\hline & & 1 & 2 & 3 & 4 \\
\hline Heart rate & $101 / \min$ & -0.7 & -0.4 & 7.7 & 3.4 \\
\hline $\begin{array}{l}\text { Blood } \\
\text { pressure }\end{array}$ & $77 \mathrm{mmHg}$ & 1.9 & 1.9 & 3.9 & 5.8 \\
\hline $\begin{array}{l}\text { Coronary } \\
\text { flow }\end{array}$ & $20 \mathrm{ml} / \mathrm{min}$ & 1.6 & -6.7 & 3.5 & 16.1 \\
\hline $\begin{array}{l}\text { Coronary } \\
\text { resistance }\end{array}$ & $\begin{array}{r}3.95 \mathrm{mmHg} \\
/ \mathrm{ml} / \mathrm{min}\end{array}$ & 0.5 & 11.4 & -0.4 & -6.4 \\
\hline$d p / d t$ & $801 \mathrm{mmHg} / \mathrm{sec}$ & 0.9 & -0.5 & 10.9 & 5.6 \\
\hline
\end{tabular}

\section{Discussion}

The present results revealed remarkable coronary vasoconstrictor effect of the left sympathetic nerve stimulation, when its inotropic and chronotropic effects were blocked with adrenergic beta blockade. This sympathetic vasoconstriction was almost abolished with adrenergic alpha blockade. The vasoconstrictor effect of the right sympathetic nerve stimulation on the left coronary artery was less remarkable. The average increase in coronary vascular resistance during the stimulation was $55.1 \%$ on the left, and $24.8 \%$ on the right sympathetic stimulation. The coronary flow returned gradually to the previous level during the stimulation, and then increased after the cessation of the stimulation without accompanying the hemodynamic changes.

On the sympathetic control of the coronary circulation, classical studies of Winbury and Green, ${ }^{1}$ Eckstein et al. ${ }^{2}$ and Gregg and Shipley ${ }^{3}$ revealed that the increase in coronary flow paralleled the increase in blood pressure, cardiac output, and cardiac work, and found the nervous control on the coronary vessel to be ambiguous. However, Okinaka et al., ${ }^{4} \mathrm{Ikeda}^{5}$ and Hashiba ${ }^{6}$ observed the initial decrease in coronary flow and increase in coronary vascular resistance during sympathetic stimulation, and suggested the vasoconstrictor effect of the sympathetic nerve. They also observed two peaks of coronary flow during and 
after the stimulation, attributing the first peak to the elevation of blood pressure and the second peak to the metabolic vasodilator substance. ${ }^{7}$ Recently Granata et al. ${ }^{8}$ observed the initial decrease in coronary flow during the left sympathetic stimulation by using a non-anesthetized dog with an implanted electromagnetic flowmeter in the coronary artery. They also indicated sympathetic coronary vasoconstriction. Berne et $a l .{ }^{9}$ also observed that the stimulation of the stellate ganglia produced an initial decrease and subsequent increase in coronary flow.

However, interpretations of these observations were complicated by the marked inotropic effect of the left sympathetic nerve and chronotropic effect of the right sympathetic nerve on the coronary circulation (Kuramoto, K. and Murata, K., to be published). Increase in heart rate is known to decrease the coronary flow at the initial phase. ${ }^{10} \mathrm{In}$ order to eliminate the myocardial effect Hashimoto et al.11 utilized a Langendorff dog preparation with ventricular fibrillation, and found the effect of epinephrine and norepinephrine to be vasoconstrictive in the initial phase. Moran and Perkins ${ }^{12}$ reported that the adrenergic beta blocking agent, dichloroisoproterenol (DCI), selectively blocked the positive inotropic and chronotropic effects of both catecholamines infused and of stimulation of the postganglionic cardiac sympathetic nerves. Siegel et al. ${ }^{13}$ stimulated the bilateral stellate ganglia after intravenous injection of DCI, and observed the initial decrease in coronary flow; they found that the direct sympathetic effect was coronary vasoconstriction. Takenaka ${ }^{14}$ also observed the vasoconstrictor effect of catecholamines following the administration of adrenergic beta blocking agent. We have observed remarkable coronary vasoconstriction during the stimulation of the left sympathetic nerve, while the effect of right sympathetic nerve is less prominent. The initial transitory decrease in coronary flow during the right sympathetic stimulation ${ }^{9}$ may be due to the effect of tachycardia, since this response elicited in the first phase was abolished after the removal of the tachycardia with propranolol.

The maximum decrease in coronary flow during the left sympathetic stimulation was observed 5 to 10 seconds after the beginning of the stimulation, when marked inotropic effect was observed in control experiments. This may suggest that the coronary artery and myocardium are innervated with the same nerve fibers.

The delayed increase in coronary flow after the sympathetic stimulation was to a lesser extent in adrenergic beta blocked dogs, in which heart the rate, blood pressure and $d p / d t$ of the left ventricular pressure remained unchanged during the stimulation. Hashimoto et $a l^{11}$ attributed the vasodilatatory effect of norepinephrine to local myocardial hypoxia. Siegel et al. ${ }^{13}$ found that DCI does not prevent the release of catecholamines from the cardiac sympathetic nerves. Thus, the late increase in coronary flow might indicate a response to myocardial hypoxia and reactive hyperemia, or it might be due to a direct metabolic effect of 
catecholamines to produce vasodilative substances.

\section{References}

1) Winbury, M.M. \& Green, D.M. Studies on the nervous and humoral control of coronary circulation. Amer. J. Physiol., 1952, 170, 555-563.

2) Eckstein, R.W., Stroud, M., Eckel, R., Dowling, C.V. \& Pritchard, W.H. Effect of control of cardiac work upon coronary flow and 0 consumption after sympathetic nerve stimulation. Amer. J. Physiol., 1950, 163, 539-544.

3) Gregg, D.E. \& Shipley, R.E. Changes in right and left coronary artery inflow with cardiac nerve stimulation. Amer. J. Physiol, 1944, 141, 382-388.

4) Okinaka, S., Ikeda, M., Hashiba, K., Murata, K., Kaneko, J., Ozawa, T., Niitani, H., Ishimi, Z., Fujii, J., Takeda, Y., Kuramoto, K., Tsuji, M. \& Terasawa, F. Studies on the control of coronary circulation. Part I. The effect of the stimulation of the nerves on the coronary circulation. Part II. The humoral effect on the coronary circulation. Amer. Heart J., 1958, 56, 319-339.

5) Ikeda, M. The nervous control of the coronary circulation. Nippon Junkankigakushi (Jap.), 1957, 21, 252-263.

6) Hashiba, K. Studies on the nervous control of the coronary circulation. II. The effect of the stimulation of the sympathetic nerve upon the coronary blood flow. Nippon Junkankigakushi (Jap.), 1958, 21, 537-544.

7) Murata, K. Studies on the neurohumoral control of the coronary circulation. Coronary vasodilative substance demonstrated in coronary venous blood samples obtained after the stimulation of the sympathetic nerve. Nippon Junkankigakushi (Jap.), 1959, 22, 910-916.

8) Granata, L., Olsson, R.A., Huvos, A. \& Gregg, D.E. Coronary inflow and oxygen usage following cardiac sympathetic nerve stimulation in anesthetized dogs. Circulat. Res., 1965, 16, 114-120.

9) Berne, R.M., DeGeest, H. \& Levy, M.N. Influence of the cardiac nerves on coronary resistance. Amer. J. Physiol., 1965, 208, 763-769.

10) Kuramoto, K., Lie, H.Y., Hosoda, S., Kurihara, H., Ikeda, M., \& Nakao, K. Effect of heart rate on coronary circulation. Tohoku J. exp. Med., 1966, 88, 235-244.

11) Hashimoto, K., Shigei, T., Imai, S., Saito, Y., Yago, N., Uei, I. \& Clark, R.E. Oxygin consumption and coronary vascular tone in the isolated fibrillating dog heart. Amer. J. Physiol., 1960, 198, 965-970.

12) Moran, N.C. \& Perkins, M.E. Adrenergic blockade of mammalian heart by dichloro analogue of isoproterenol. J. Pharmacol. exp. Ther., 1958, 124, 223-237.

13) Siegel, J.H., Gilmore, J.P. \& Sarnoff, S.J. Myocardial extraction and production of catecholamines. Circulat. Res., 1961, 9, 1336-1350.

14) Takenaka, F. Effects of epinephrine and beta adrenergic blocking agents on coronary circulation and myocardial metabolism. Naunyn-Schmiedeberg's Arch. exp. Path. Pharmak., 1966, 252, 407-417. 